negatively charged acidic groups by the strong electrostatic fields present, and their apparent activity coefficient is thus considerably lowered in comparison with that in corresponding solutions of sodium salts of simple mineral acids. This typo of binding is called "site-binding"4.

The binding of the sodium ion can be estimated by comparing the value of the apparent activity of this ion in the poly-acid solution with that in a standard solution of sodium chloride containing the same concentration of sodium. The apparent activity of the sodium can be determined by means of a glass electrode sensitive to sodium $^{5}$. While there are no special difficulties in using this electrode in solutions of simple electrolytes, there are possible sources of interference with measurements in solutions of macromolecules. The unknown value of the liquid junction potential, which may differ significantly from that in standard solutions of sodium chloride, must be considered one of the most important. In order to prove that the low value of the apparent activity of the sodium ion in solutions of the sodium salts of the poly-acids results entirely from site-binding, an attempt has been made to demonstrate the binding indirectly.

Because the site-binding is purely electrostatic, it might be expected that a polyvalent cation having a much higher charge density would replace that of sodium bound in the neighbourhood of the charged groups of the poly-acid. As all the bound sodium could thus be liberated, it would be possible to infer the amount of it from the difference between the apparent activity of the sodium ion in the original solution and that in a solution in which all the sodium ions had been liberated by the addition of an excess of a polyvalent cation.

The sodium salt of heparin ('Heparin Spofa', twice recrystallized) was used. To determine this concentration of the acidic groups, solutions of the sodium salt were passed through a column of 'Dowex 50' in the hydrogen form. Completeness of the ion exchange was confirmed by flame photometry. Solutions of the free acid thus obtained were titrated with sodium hydroxide solutions free from carbon dioxide. The apparent activity of the sodium ion was measured with a glass semi-microelcctrode sensitive to sodium and a saturated calomel electrode. The e.m.f. of the cell thus formed was standardized over the range $0.01-0.2 \mathrm{M}$ with solutions of sodium chloride, and found to be reproducible to within $0.3 \mathrm{mV}$. The trivalent ion of lanthanum in the form of a $0 \cdot 4 \mathrm{M}$ chloride solution was used as the polyvalent cation. The glass electrode was insensitive towards the lanthanum ion in the range of concentrations used.

Because the potential of the glass electrode becomes dependent on $p \mathrm{H}$ at $p \mathrm{H}$ below 6, care had to be taken that the poly-acid solution was completely noutralized; otherwise, the lanthanum ion would have liberated not only the sodium ion, but also that of hydrogen. For the same reason, an atmosphere of nitrogen was used to guard against contamination by carbon dioxide.

The concentration of free sodium ions in a solution of the sodium salt of heparin is plotted in Fig. 1 as a function of the concentration of lanthanum chloride. The measurements have been corrected for the change of volume and for variations of ionic strength. It will be noted that an excess of lanthanum is necessary to liberate all the bound sodium. An identical curve would have been obtained if the solution of the sodium salt had been prepared by neutralizing the free heparin. The values found for binding of the sodium ion by heparin are comparable with those obtaincd by Ascoli et al. ${ }^{6}$ by a different technique.

If the sodium salts of hyaluronic aeid and deoxyribonucleic acid are used with the cation exchange resin 'Dowex $50 W-X 8$ ' $(200-400$ mesh $)$ in the sodium form instead of heparin, similar curves are obtained. The resin had to be suspended in a $0.01 \mathrm{M}$ solution of sodium chloride.

Applications of this method are not limited to binding of the sodium ion by the poly-acids. It can also be applied to systems in which binding other than site-binding is

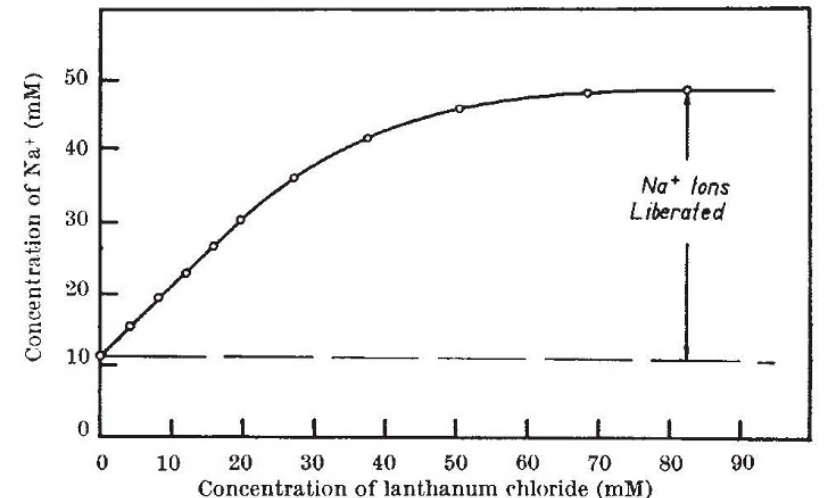

Fig. 1. Concentration of the free sodium ion in a solution of the sodium salt of heparin as a function of the concentration of lanthanum chloride. The concentration of the acidic groups of heparin as well as that of
sodium was $48 \mathrm{mM}$.

involved, as with ethylenediamine tetraacetic acid or adenosine triphosphate. Moreover, because of this high selectivity of the glass electrode, the determination can also be carried out if cations other than sodium are present. Preliminary results indicate that this method, slightly modified, could also be used to analyse this binding of the sodium ion in biological systems.

V. PaLATÝ

Institute of Physiology,

Czechoslovak Academy of Sciences,

Prague.

${ }^{1}$ Cope, F. W., Proc. U.S. Nat. Acad. Sci., 54, 225 (1965).

2 Ling, G. N., Fed. Proc., 24, Suppl. No. 15, S103 (1965). ${ }^{3}$ Friedman, S. M., and Friedman, C. L., in Electrolytes and Cardiovascular
Diseases, edit. by Bajusz, E., 327 (S. Karger, Basle, 1965).

' Harris, F. F., and Rice, S. A., J. Phys. Chem., 58, 725 (1954).

${ }^{5}$ Eisenman, G., Rudin, D. O., and Casby, J. U., Science, 126, 831 (1957).

' Ascoli, F., Botré, C., and Liquori, A. M., J. Phys. Chem., 65, 1991 (1961).

\section{Nomenclature of Elements}

WOLFENDEN $^{1}$ has suggested changes in the names of the elements so as to ensure that the names of all the metals. but none of the non-metals, end in ium. For example, he proposes the new names platinium and helion. If this desirable proposal is to be adopted, a criterion is necessary to distinguish metals from non-motals.

An element can be defined as a metal if, at room temperature and pressure, it has a low electrical resistivity which increases with temperature. By this criterion there are twenty-two non-metals:

$$
\begin{aligned}
& \text { H } \mathrm{He} \\
& \begin{array}{llllll}
B & C & \mathbf{N} & \mathrm{O} & \mathbf{F} & \mathrm{Ne}
\end{array} \\
& \text { Si P S Cl Ar } \\
& \text { Ge se } \mathrm{Br} \mathrm{Kr} \\
& \text { Te I Xe } \\
& \text { At } \mathrm{Rn}
\end{aligned}
$$

Changes in the names of elements in addition to those proposed by Wolfenden would be: germanon ${ }^{2}$, arsenium ${ }^{3}$, selenon ${ }^{4}$ and telluron ${ }^{5}$. The references are to resistivity data for pure samples of these elements.

Least satisfactory is the choice of a name for tin, for below $13^{\circ} \mathrm{C}$ the stable phase is a non-metal ${ }^{6,7}$.

Department of Metallurgy,

\section{R. Shuttieworth}

University of Leeds.

' Wolfenden, A., Nature, 211,632 (1966).

2 Hogarth, C. A., in Materials used in Semicondurtor Devires, edit. by Hogarth, C. A., 13 (J., Wiley, New York, 1965).

${ }^{3}$ Taylor, J. B., Rennet।, S. T., and Hedding, R. D., J. Phys. Chem. Solids, 26, 69 (1965).

- Jenkins, A., in Materials uspd in Semiconductor Devices, edit. by Hogarth, C. A., 58 (J. Wiley, New York, 3965).

'McKay, R. W., and Gravelle, W. F., Canad. J. Phys., 39, 534 (1961).

- Ewald, A. W., and Tufte, 0. N., J. Phys. Chem. Solids, 8, 523 (1959).

${ }^{7}$ Ellwood, E. C., in T'in and its Alloys, edit. by lledges, E. S., 56 (Fdward Arnold, Jondon, 1960). 